\title{
Characterization of Lithographically Printed Resistive Strain Gauges
}

\author{
Gareth I. Hay, Peter S. A. Evans, Member, IEEE, David J. Harrison, Darren Southee, George Simpson, and \\ Paul M. Harrey
}

\begin{abstract}
This paper reports progress in sensor fabrication by the conductive lithographic film (CLF) printing process. Work describing strain-sensitive structures manufactured using a modified printing process and conductive inks is addressed. The performance of a "single-ink" strain-sensitive structure when printed on six alternative substrates (GlossArt, PolyArt, Teslin, Mylar C, Melinex, and Kapton) is analyzed. Though not intending to compete with conventional gauges in high-tolerance measurement, the structures exhibit properties that indicate suitability for novel applications.
\end{abstract}

Index Terms-Conductive lithographic film (CLF), offset lithography, printed sensors, printed strain gauges.

\section{INTRODUCTION}

$\mathbf{R}$ ESISTIVE strain gauges are a popular and reliable method for determining localized strain in manufacturing and engineering industries. Average unit strain, capable of being determined using strain gauges, can be summarized as the "total deformation of a body in a given direction divided by the original length in that direction"[1]. The operation of resistive strain gauges relies on the change in resistance of a conductor when a load is applied.

Common commercially available strain gauge structures are manufactured using conventional photo-resist and acid-etching processes. The disadvantages associated with these techniques are generation of toxic effluents and the slow speed of production.

\section{A. CLF Process}

The conductive lithographic film (CLF) process was originally developed as an alternative for etched resin-laminate circuit boards. The technique utilizes standard offset lithographic printing technology used in the mass production of books and magazines. The CLF process possesses a number of key advantages over more traditional forms of electronic circuit board fabrication [2]:

\footnotetext{
Manuscript received February 13, 2004; revised August 3, 2004. The associate editor coordinating the review of this paper and approving it for publication was Dr. Errol EerNisse.

G. I. Hay, P. S. A. Evans, D. J. Harrison, D. Southee, and G. Simpson are with the School of Engineering and Design, Brunel University, Middlesex UB8 3PH, U.K. (e-mail: gareth.hay@brunel.ac.uk; peter.evans@brunel.ac.uk; david.harrison@brunel.ac.uk; darren.southee@brunel.ac.uk; george.simpson@ brunel.ac.uk)

P. M. Harrey is with the Rinstrum Pty Ltd., Queensland, Australia, 4110 (e-mail: mitchellharrey@ hotmail.com)

Digital Object Identifier 10.1109/JSEN.2005.845209
}
- high production speed (6000-10000 impres- sions/hour);
- $\quad$ good resolution of image (80-100- $\mu$ track with $60-\mu$ gap easily achievable);
- $\quad$ low cost (low ink volume determining that substrate material proves the largest expense);
- $\quad$ ability to produce flexible electronic circuits and sys- tems;
- $\quad$ reduced environmental impact [less energy, reduction in material use, easier disposal, and toxic heavy metals (e.g., lead) eliminated].

Electrically conductive ink films can also be printed on a wide range of flexible substrates including paper and polymer films.

A range of passive components and sensor structures have been manufactured by the CLF process by designing structures that exploit the electrical properties of the printed ink films [3]-[5]. CLF conductors printed on flexible polymer materials have been found to exhibit a change in their electrical resistance when deformed, lending themselves to resistive strain gauge applications. The aim of this research is to identify the best substrates for printed strain structures and to understand in detail the electrical and mechanical properties of the ink on different substrates. Changes in structure resistance due to strain, relative humidity and temperature is described in this paper.

\section{B. Previous Work}

Polymer thick-film resistors have been achieved in the past by depositing high-resistance films by means of screen printing on various substrates. Unlike the approach adopted by this work, previous printed strain sensor research mainly concerns the deposition of solid resistive layers as opposed to a single track [6]-[11].

"Solid layer" structures have been deposited directly onto beams to which measurement loads are applied or onto thin metallic strips subsequently attached to beams. These processes have achieved respectable results; however, due to the nature of the films involved, often high-firing/curing temperatures are required. CLF deposited films are air curable and the implementation of raised curing temperatures is optional as opposed to essential.

The capability of printing directly onto thin substrates by the CLF process, via a sheet fed press, enables structures to be manufactured in bulk and bonded to test samples following conventional strain gauge application techniques. 


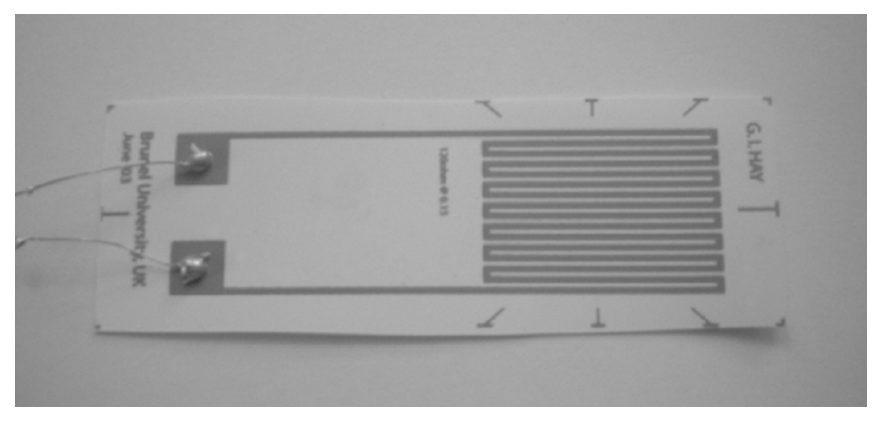

Fig. 1. Printed strain-sensitive structure.

\section{EXPERIMENTAL METHODS}

Early prototypes of printed strain-sensitive structures proved to be acceptably sensitive when deformed. However, a large degree of drift was noticed during repeated cycling. Mechanical settling of the ink or changes in ambient temperature or relative humidity were thought to be the cause of such drift. In response, a series of experiments have been undertaken to identify the amount of drift caused by these factors.

\section{A. Fabrication of Structures}

Strain-sensitive structures (Fig. 1) were formed by lithographically printing silver-loaded conductive ink onto substrates, using the practice of over printing three times to ensure an even, approximately $3-\mu$ thick, ink film throughout. The apparatus used for this operation was a sheet-fed lithographic printing press, model Heidelberg GTO46. A novel silver-loaded conductive ink developed by Brunel University was used in printing trials. The ink has been described in previous work [12] and consists of an electrically conductive silver metal particulate, suspended in an organic resin. The ink formulation is engineered to be compatible with a wide range of organic and synthetic substrate materials and the rheological properties of the ink have been designed to be compatible with standard offset lithographic printing machines.

Ink layers deposited by the CLF process have a thickness between 3-5 $\mu$, which may be compared to $\approx 50 \mu$ for thick-film conductors formed by screen printing processes and $\approx 35-75 \mu$ of copper typically laminated onto conventional FR2/FR4 circuit boards.

The ink constitutes $80 \%$ silver particulate by weight $(1-\mu$ mean size) and achieves a sheet resistance of approximately $0.15 \Omega / \square$ (dependant on substrate), which is in agreement with previous work on conductive mixtures [13]. The vehicle portion of the ink comprises a large proportion of organic alkyd resin with traces of solvent and anti oxidant agents.

The gauge sensing elements were dimensioned $22 \times 15.5 \mathrm{~mm}$ with track and gap dimensions of $0.5 \mathrm{~mm}$.

Substrate thickness is a major consideration in strain sensor design. To achieve high accuracy, sensors should employ the thinnest substrate possible allowing conducting elements to lie the smallest distance possible above the test beam surface, thereby reducing the degree of error created by substrate deformation. Table I details the six substrates chosen for this work with respect to: material, thickness, and nominal gauge
TABLE I

SubSTRATE CHARACTERISTICS AND NOMINAL GAUGE RESISTANCE

\begin{tabular}{cccc}
\hline \hline Substrate & Material & $\begin{array}{c}\text { Thickness } \\
(\mu \mathrm{m})\end{array}$ & $\begin{array}{c}\text { Nominal gauge } \\
\text { resistance }(\Omega)\end{array}$ \\
\hline GlossArt & Coated paper & 100 & $45-80$ \\
PolyArt & Polyethylene & 200 & $60-70$ \\
Teslin & $\begin{array}{c}\text { Polyethylene }+ \\
\text { silica filler }\end{array}$ & 191 & $100-110$ \\
Mylar C & Polyester & 36 & $200-240$ \\
Melinex & Polyester & 7 & $170-245$ \\
Kapton & Polyimide & 6 & $125-150$ \\
\hline
\end{tabular}

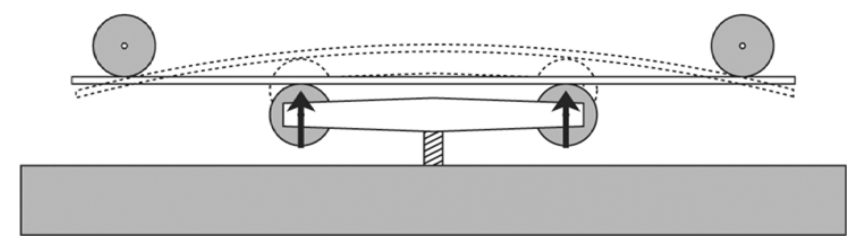

Fig. 2. Four-point deflection jig.

resistance. Gauge resistance varies greatly depending on the surface porosity of the substrate.

After printing, samples were allowed to dry in air for seven days before constantan contact wires were attached using a commercially available conductive adhesive (Circuitworks CW2400). Once the curing time for the adhesive recommended by the manufacture was completed, samples were oven heated at $70{ }^{\circ} \mathrm{C}$ for $15 \mathrm{~min}$ to evaporate any remaining solvent in the ink films.

\section{B. Resistance-Strain Measurements}

Aluminum beams $(6.5 \times 34.5 \times 600 \mathrm{~mm})$ were employed for the resistance-strain measurements. Beams were prepared before the introduction of samples by following standard strain gauge application procedures:

- application area treated using emery cloth and ammonia water;

- $\quad$ residue removed using phosphoric acid applied with cotton;

- $\quad$ area finally neutralized using ammonia water,

The substrate surface to be bonded to the beam was coated with an adhesion catalyst (200 Catalyst-C), which was allowed to dry before cyanoacrylate adhesive (M-Bond 200) was used to form a bond, taking care to eliminate the presence of air pockets between substrate and beam. The assembly was allowed to cure for $1 \mathrm{~h}$ before soldering lead wires to the contact wires. The nominal resistance of printed sensor structures varied depending on the substrate material from $45-240 \Omega$.

A four-point deflection jig (Fig. 2) was employed to ensure uniform beam deflection during trials. Each structure was exposed to four repetitive straining and relaxing cycles from $0-2000-\mu \varepsilon$ while resistance measurements were recorded at $100-\mu \varepsilon$ intervals using a Fluke 189 True RMS Multimeter.

\section{Temperature Resistance and Relative-Humidity Resistance Measurements}

Temperature resistance and relative-humidity resistance tests were conducted in order to determine how the resistance of ink films varied when exposed to extremes of temperature and 


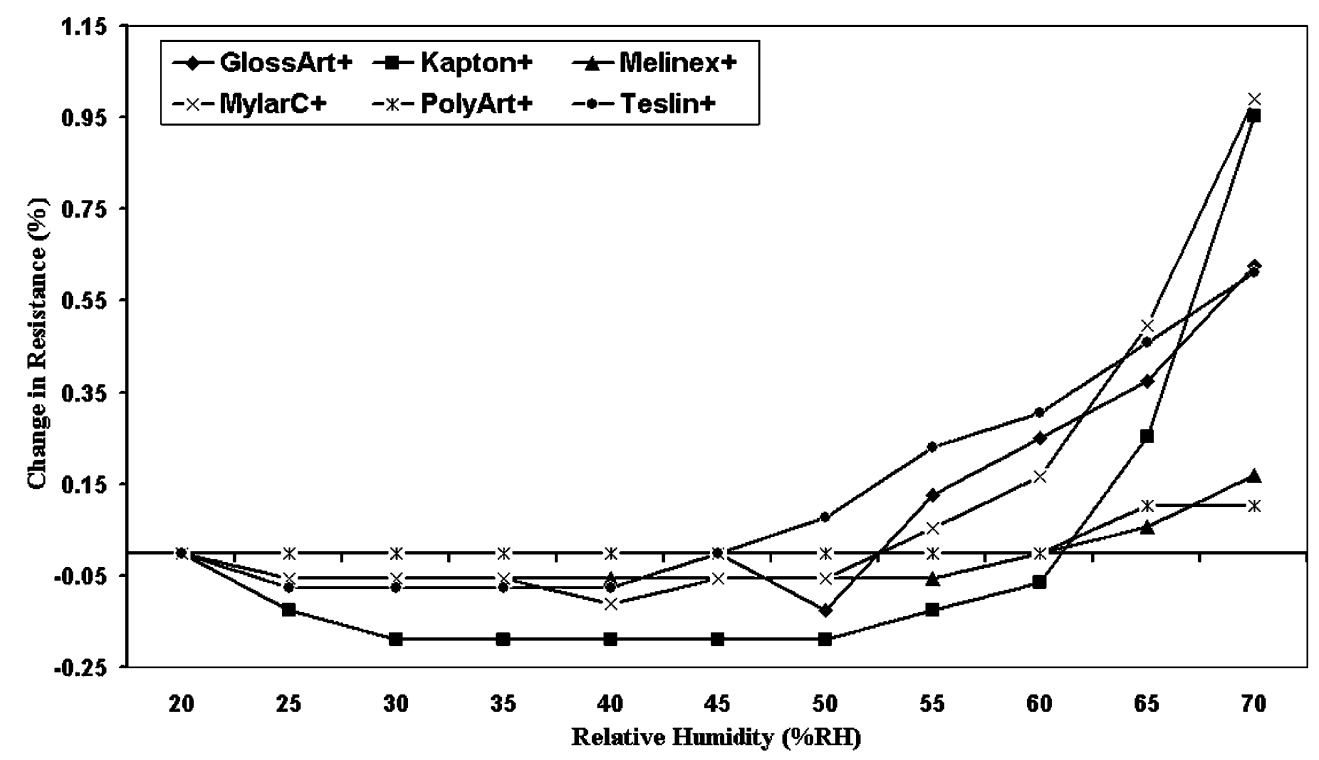

Fig. 3. Typical relative-humidity resistance plot for each substrate.

relative humidity. Single-track ink film structures printed and prepared in the same manner as the strain-sensitive structures were employed, and as with the strain structures initial resistance varied depending on the substrate, from approximately $15-100 \Omega$.

For the purpose of humidity testing, a humidity chamber/generator (Digilog Instruments, Vaportron $\mathrm{H}-100 \mathrm{~L}$ ) was adjusted to maintain a constant $23{ }^{\circ} \mathrm{C}$, while relative humidity was cycled in 5\% RH steps from 20\%-70\% RH over three cycles. Resistance measurements were recorded at these intervals using the Fluke multimeter. Temperature testing followed a similar trend; relative humidity was maintained at a constant $40 \% \mathrm{RH}$ while temperature was incremented and decremented from $15{ }^{\circ} \mathrm{C}$ to $40{ }^{\circ} \mathrm{C}$ in $5^{\circ} \mathrm{C}$ steps over three repetitive cycles. Again, resistance measurements were recorded at every interval.

\section{RESULTS}

\section{A. Relative-Humidity Resistance}

Fig. 3 details typical responses gained from samples printed on each of the six different substrates while undergoing relativehumidity resistance testing.

Changes to resistance due to relative humidity ( $\mathrm{RH})$ were nonlinear and became significant at humidity levels above $50 \%$ $\mathrm{RH}$. The greatest change in resistance due to humidity occurred with structures printed on Mylar $\mathrm{C}$ and amounted to approximately $0.95 \%$ of the initial resistance.

Referring to Table II, it is apparent that structures printed on Kapton experienced the greatest change in resistance due to humidity at $50 \% \mathrm{RH}(-0.191 \%$ of initial resistance). The resistance of PolyArt remained stable under these conditions. Between the range of 50\%-70\% RH the resistance of all substrates increased dramatically. Mylar C experienced the greatest increase while PolyArt remained the least affected substrate.

Relative humidity coefficient of resistance (RHCR) values have been calculated by considering change is resistance values
TABLE II

Percent Change IN Resistance at 50\% RH AND $70 \%$ RH. ALSO RH COEFFICIENT OF RESISTANCE

\begin{tabular}{|c|c|c|c|}
\hline Substrate & $\begin{array}{l}\% \Delta \mathrm{R} \text { at } \\
50 \% \mathrm{RH}\end{array}$ & $\begin{array}{l}\% \Delta \mathrm{R} \text { at } \\
70 \% \mathrm{RH}\end{array}$ & $\begin{array}{c}\text { RHCR } \\
\left(* 10^{-3} / \% \text { RH }\right)\end{array}$ \\
\hline$\overline{\text { GlossArt }}$ & -0.125 & 0.626 & -0.0417 \\
\hline PolyArt & 0 & 0.104 & 0 \\
\hline Teslin & 0.076 & 0.612 & 0.0255 \\
\hline Mylar C & -0.055 & 0.991 & -0.0184 \\
\hline Melinex & -0.056 & 0.168 & -0.0187 \\
\hline Kapton & -0.191 & 0.953 & -0.6353 \\
\hline
\end{tabular}

between $20 \%-50 \%$ RH due to the dramatic increase in resistances at higher RH levels and are detailed in Table II

$$
\mathrm{RHCR}=\left(\frac{1}{R}\right) *\left(\frac{\Delta R}{\Delta \% \mathrm{RH}}\right) .
$$

RHCR values were calculated using the equation above, where, $\mathrm{R}$ represents initial resistance, $\Delta \mathrm{R}$ change in resistance and $\Delta \%$ RH change in relative humidity.

\section{B. Temperature Resistance}

Typical results gained during temperature-resistance tests for structures printed on each of the six substrates are illustrated in Fig. 4. The trend of increasing resistance with temperature can be observed.

As with data gained from relative-humidity resistance tests, results show a large degree on nonlinearity, this becomes more noticeable through the range of $30{ }^{\circ} \mathrm{C}-40{ }^{\circ} \mathrm{C}$ where resistance increases at an accelerated rate. Table III details in a numerical form the large acceleration in resistance increase over this range.

Structures printed on Kapton were the least affected substrate during testing while those printed on PolyArt were the most affected over the range $0{ }^{\circ} \mathrm{C}-30{ }^{\circ} \mathrm{C}$. Above $35^{\circ} \mathrm{C}$, the resistance of Mylar C samples increased rapidly, this trend was noticed during all temperature tests using this substrate.

Due to the extreme nonlinearity experienced at high temperatures, the temperature coefficient of resistance (TCR) for each 


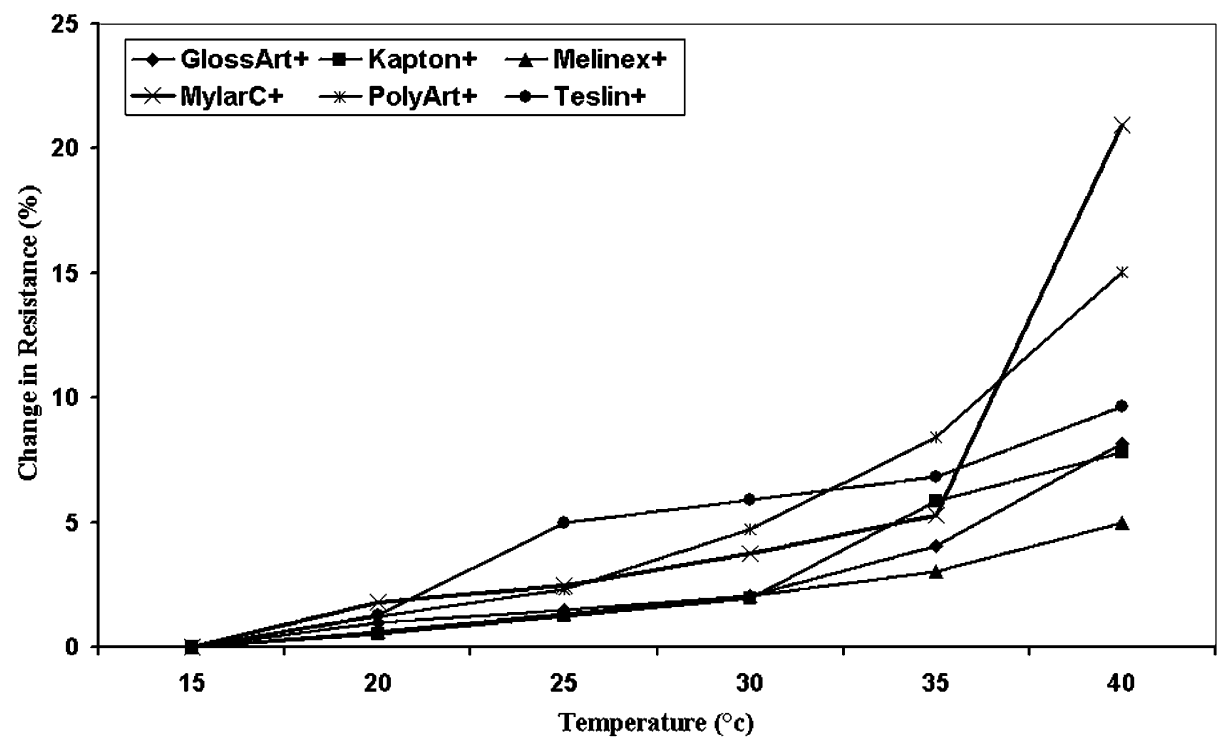

Fig. 4. Typical temperature-resistance plot for each substrate.

TABLE III

Percent Change in Resistance at $30{ }^{\circ} \mathrm{C}$ And $40{ }^{\circ} \mathrm{C}$. Also TEMPERATURE COEFFICIENT OF RESISTANCE

\begin{tabular}{cccc}
\hline Substrate & $\% \Delta \mathrm{R}-30^{\circ} \mathrm{C}$ & $\% \Delta \mathrm{R}-40^{\circ} \mathrm{C}$ & $\begin{array}{c}\mathrm{TCR} \\
\left(* 10^{-3} /{ }^{\circ} \mathrm{C}\right)\end{array}$ \\
\hline GlossArt & 2.058 & 8.162 & 2.023 \\
PolyArt & 4.715 & 15.054 & 4.218 \\
Teslin & 5.879 & 9.671 & 3.413 \\
Mylar C & 3.759 & 20.930 & 2.644 \\
Melinex & 2.065 & 5.004 & 1.509 \\
Kapton & 1.954 & 7.815 & 2.931 \\
\hline
\end{tabular}

substrate was determined using the equation below, by considering results in the range $15{ }^{\circ} \mathrm{C}-35^{\circ} \mathrm{C}$ and are detailed in Table III

$$
\alpha=\left(\frac{1}{R}\right) *\left(\frac{\Delta R}{\Delta T}\right) .
$$

In the TCR equation, $\alpha$ represents the temperature coefficient of resistance, $R$ represents the nominal resistance and $\Delta R$ and $\Delta \mathrm{T}$ represent the change in resistance and the change in temperature, respectively.

It is possible to determine that over this range that samples printed on PolyArt were affected the most due to changes in ambient temperature while structures deposited on Melinex were affected the least. It must be noted that all samples were printed at the same time with the same batch of ink and, therefore, any changes in resistance due to either relative humidity or temperature reflects the compatibility of ink to substrate. Substrates such as Teslin, PolyArt, and GlossArt have been developed for graphical applications in commercial printing. Substrates such as Melinex, Mylar C, and Kapton are engineering materials specified for electronic applications.

\section{Strain Resistance}

The strain-resistance response of the structures are depicted in Figs. 5 and 6. These illustrations chart fractional change in resistance against micro strain for the various printed strain-sensitive structures evaluated.
The characteristics of sensors printed on Teslin are plotted as a separate graph as the sensitivity achieved with these samples were significantly greater than those achieved with other substrate materials.

It is clear from the illustrations that all samples exhibit nonlinear characteristics. In order to compare the degree of linearity between samples, Pearson's product moment correlation coefficients (PPMCC) were generated from the data and are depicted in Table IV. From these values, it was determined that the response of Teslin sensors demonstrated the greatest degree of linearity while Mylar $\mathrm{C}$ sensors demonstrated the worst linearity. Measurements of linearity for all printed structures are comparable to other printed thick-film sensors [7], [14].

The data displayed in Figs. 5 and 6 was used to generate gauge factor values for each printed structure. The gauge factor (GF) is derived to numerically represent the sensitivity of a structure by considering the change in resistance, nominal resistance and applied strain

$$
\mathrm{GF}=\frac{\frac{\Delta R}{\varepsilon}}{\varepsilon} .
$$

GF values were derived using the equation above, where $\Delta R / R$ represents the fractional change in resistance and $\varepsilon$ represents the applied strain and are listed in Table IV.

GF values confirm the trends represented in Figs. 5 and 6, indicating that structures printed on Teslin are the most sensitive, achieving a gauge factor of approximately 52 . Structures printed on Kapton are least sensitive, achieving a gauge factor of approximately 1.7. Structures printed on the remaining substrates possess gauge factors between 1.8 and 6.3.

Metal foil gauges possess gauge factor values between 2-4 while gauge factor results obtained by screen-printed strain sensors range from 3-13. It must be noted, however, that the structures developed in this work differ greatly from those developed in previous screen printing research as these structures rely on a change in resistance of a single conductive track a opposed to a "solid" high-resistance ink film [6]-[11], [14]. High-gauge 


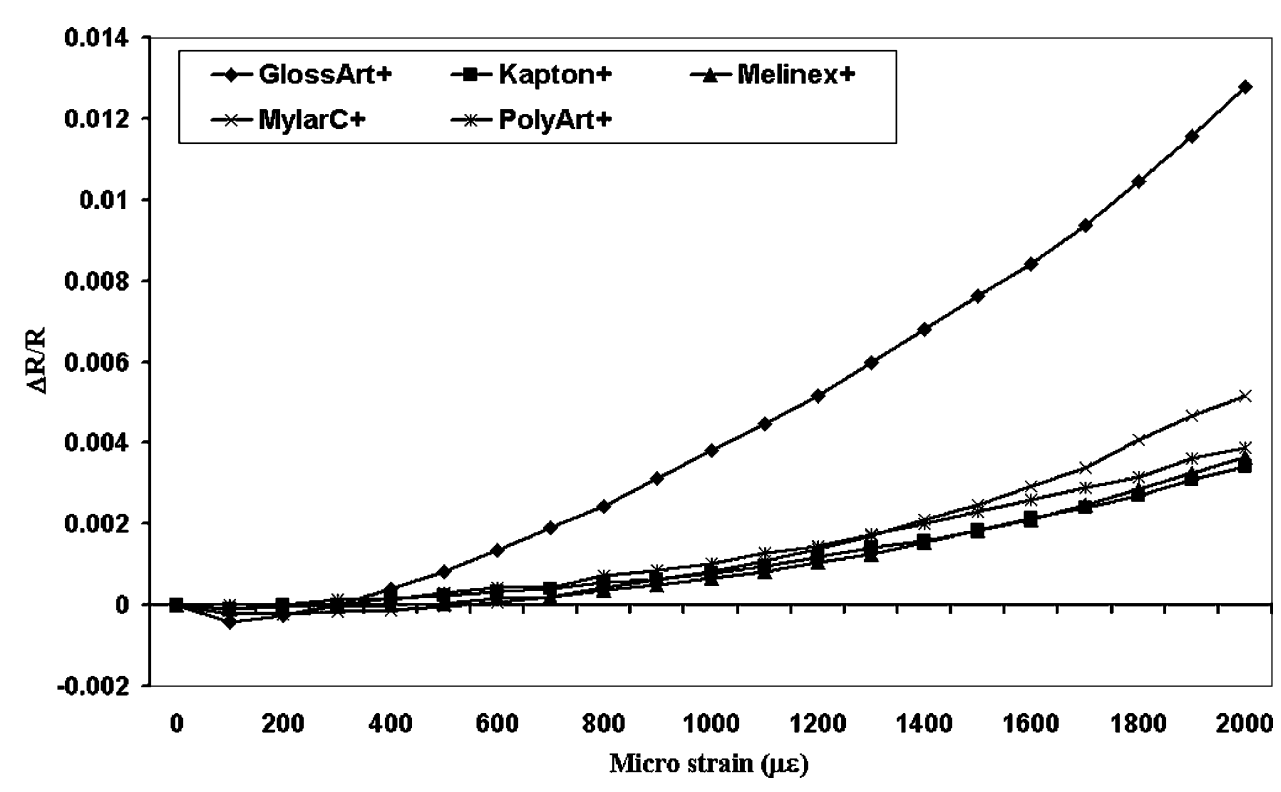

Fig. 5. Typical strain-resistance plot for each substrate.

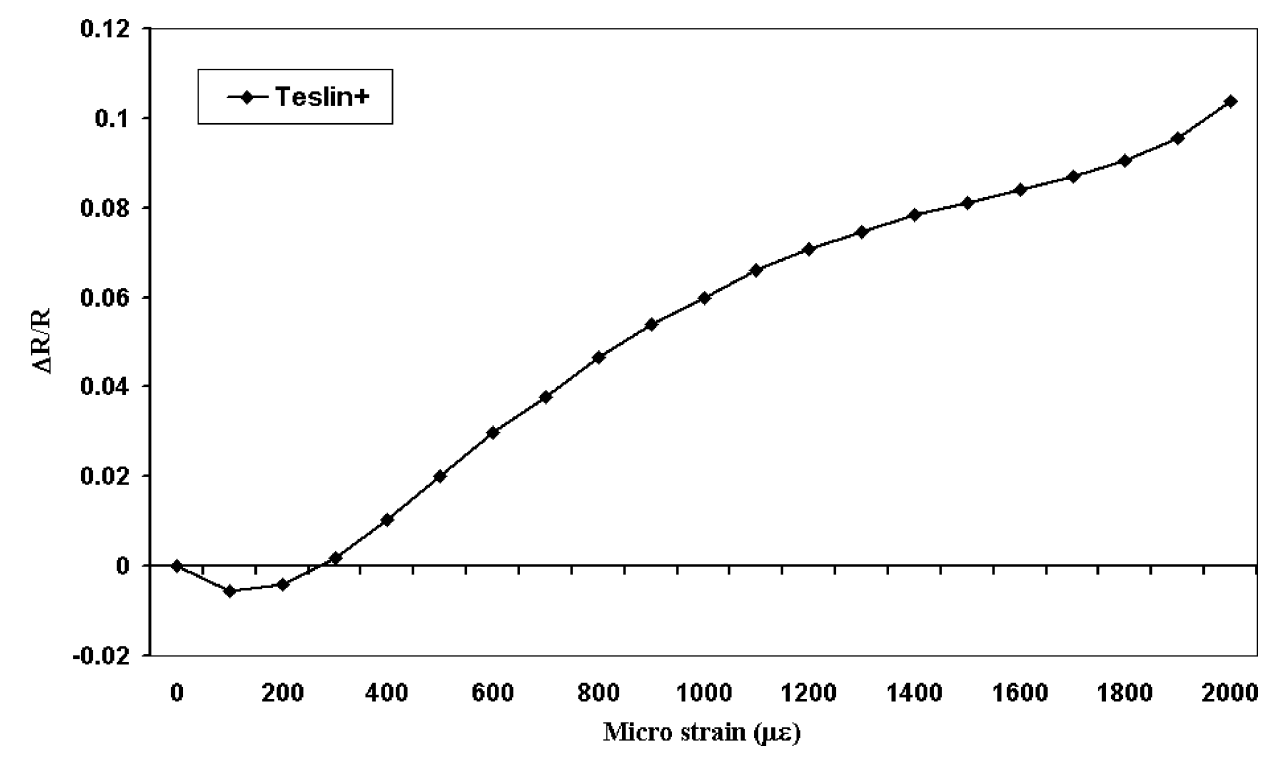

Fig. 6. Typical strain-resistance plot for Teslin.

TABLE IV

Gauge Factor and Pearson's Product Moment Correlation COEFFICIENT FOR EACH SUBSTRATE

\begin{tabular}{ccc}
\hline Substrate & Gauge Factor & PPMCC \\
\hline GlossArt & 6.388 & 0.961 \\
PolyArt & 1.947 & 0.942 \\
Teslin & 51.851 & 0.968 \\
Mylar C & 2.582 & 0.885 \\
Melinex & 1.832 & 0.890 \\
Kapton & 1.711 & 0.928 \\
\hline
\end{tabular}

factor values recorded for structures printed on Teslin suggest a good compatibility between ink and substrate for strain sensing applications.

Figs. 7 and 8 represent typical repeatability plots for GlossArt and Kapton, respectively.

Readings of fractional change in resistance taken from all structures were consistent over repeated loading-unloading cy- cles. Figs. 7 and 8 depict the reproducibility of all substrate responses to strain despite possessing different characteristics. It can be seen from Fig. 7 that a large degree of hysteresis occurs on the first cycle, while subsequent cycles incurred a small amount of drift. This is comparable to the results obtained from Mylar C and PolyArt samples. Fig. 8 indicates continuous cyclical hysteresis but also significant drift between cycles. These trends are also apparent in sensors printed on Teslin and Melinex substrates.

\section{CONCLUSION}

A range of strain-sensitive structures fabricated by the CLF printing process have been evaluated. The results demonstrate that these structures exhibit comparable strain-resistance responses to similar sensors fabricated by conventional screen-printing techniques. 


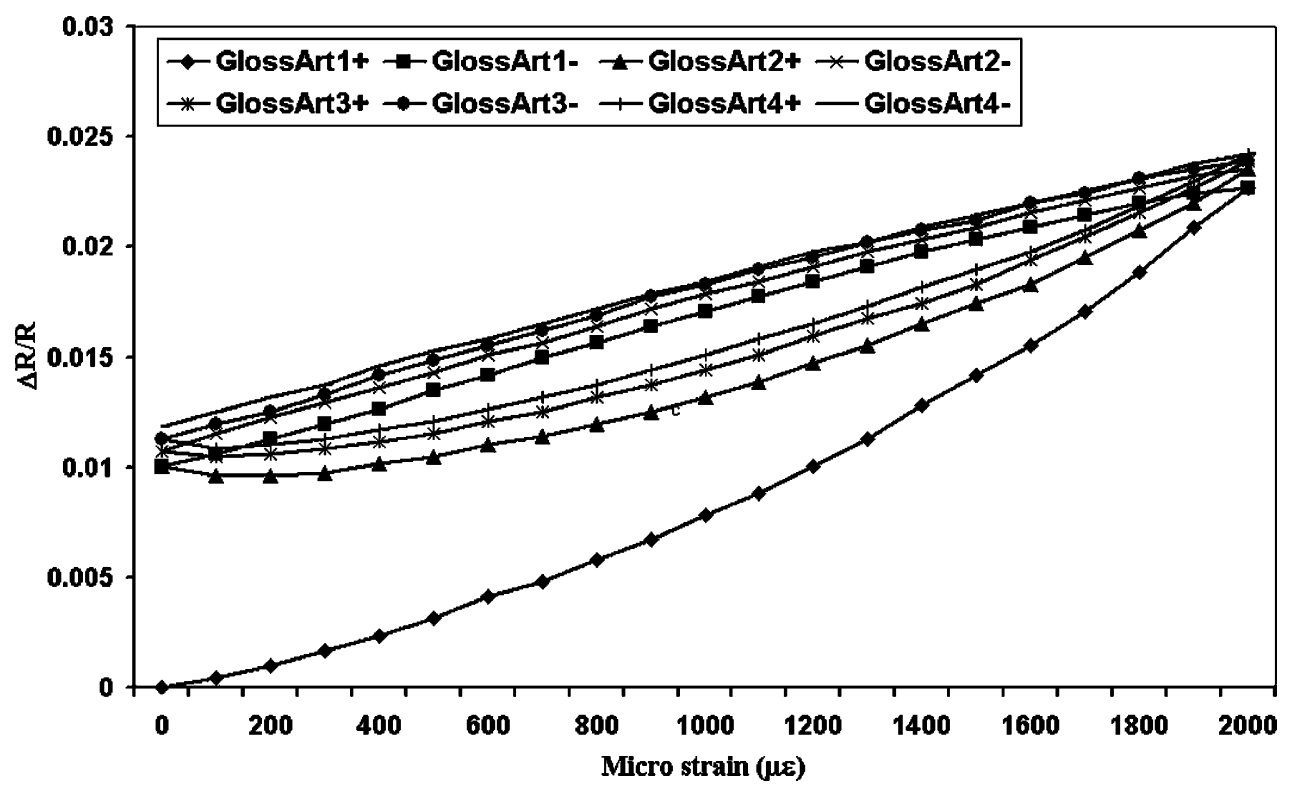

Fig. 7. Typical repeatability plot for GlossArt.

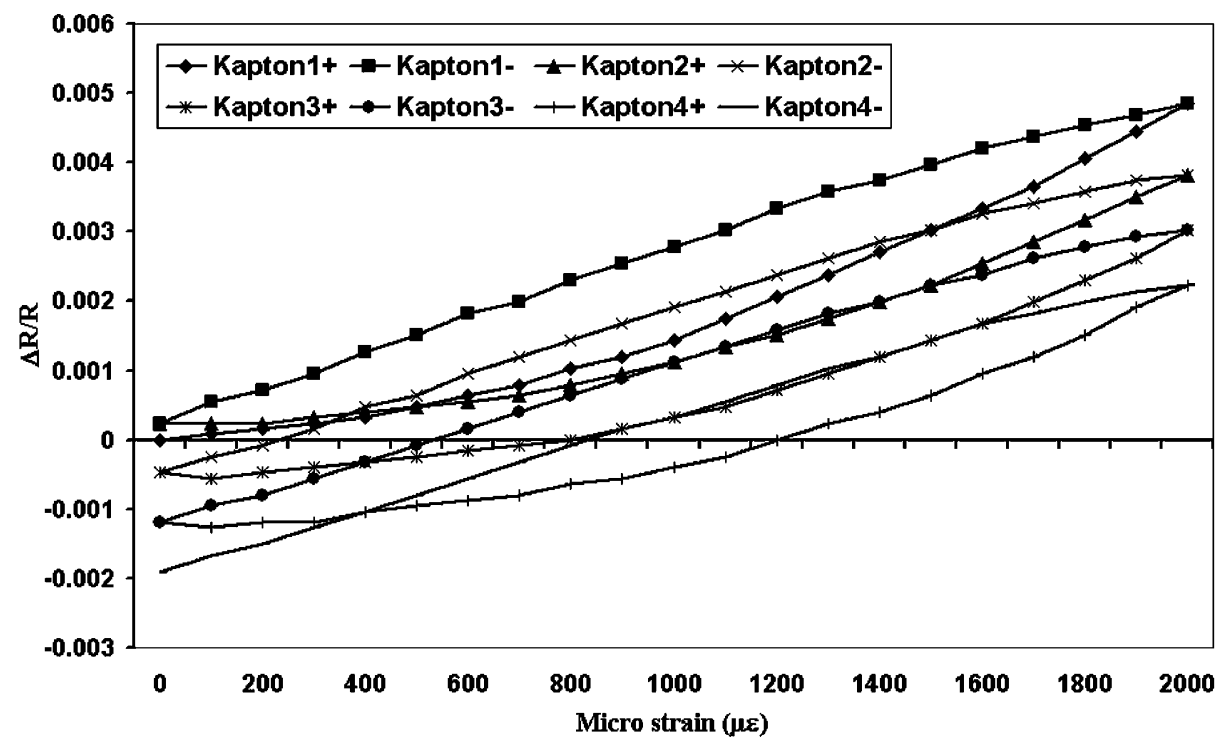

Fig. 8. Typical repeatability plot for Kapton.

The response of these structures to changes in temperature and relative humidity has also been quantified. Changes in sensor resistance due to changes in relative humidity prove to be negligible when compared to the changes in resistance caused by changes in ambient temperature. This is quantifiable when comparing the coefficients of resistance for temperature and relative humidity for structures printed on each substrate. By comparing the TCR value for Teslin printed structures $\left(4.218 * 10^{-3} /{ }^{\circ} \mathrm{C}\right)$ to the corresponding RHCR $\left(0.0255 * 10^{-3} / \% \mathrm{RH}\right)$, it can be determined that the change in resistance due to changes in relative humidity is several orders of magnitude less than the change in resistance due to changes in temperature. Similar results were obtained with samples printed on the remaining substrates.

During strain-resistance measurements, local monitoring of ambient temperature and relative humidity was performed to ensure that these variables did not significantly affect the data being gathered. Temperature fluctuated from $22.1{ }^{\circ} \mathrm{C}-22.8^{\circ} \mathrm{C}$ while relative humidity varied from $36.8 \%-37.9 \%$ RH. By considering the changes in temperature and relative humidity during the straining cycles and considering the coefficient for temperature and relative humidity for the Teslin printed sample, it is possible to determine that the sum change in resistance due to environmental changes amounts to less that $0.05 \%$ of initial resistance of the structure. This result is similar for structures printed on all substrates; hence, changes in resistance during straining cycles due to environmental alterations can be eliminated from the results as they are too small to be of significant importance.

The wide variation in gauge factor values noted between the sensors printed on different substrates is ascribed to a combination of the following factors:

- $\quad$ substrate microstructure

- $\quad$ substrate surface porosity;

- $\quad$ substrate surface roughness. 


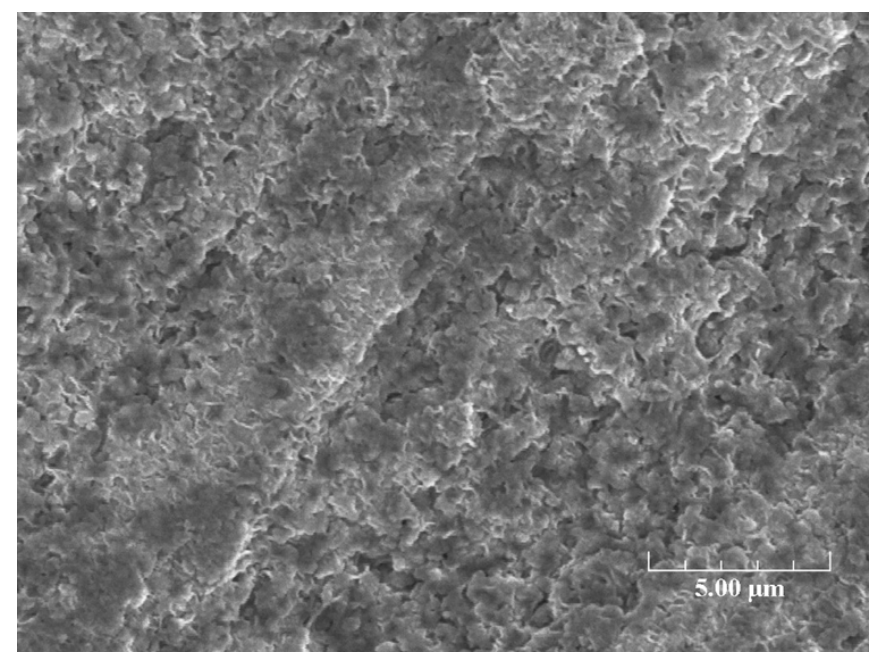

Fig. 9. Surface SEM of Teslin substrate.

Surface roughness influences the effective surface area of the substrate material, this can modify the particulate density in the cured ink film. The variations in particulate concentration in the cured ink film appear to lead to variations in the initial sheet resistance of printed structures, but do not appear to significantly affect the gauge factor values of the structures. Mylar C (Fig. 10) exhibits a very low-surface roughness; hence, ink film penetration into the substrate surface is restricted. This has the consequence of elevating nominal resistance value for structures printed on this material as the particle/vehicle ratio is greater than that which occurs on porous substrates. Teslin (Fig. 9) exhibits a high-surface roughness, as such nominal gauge resistance values are less than structures printed on "smoother" substrates.

Porosity of the substrate material can influence gauge factor values and nominal structure resistance. For example, highly porous substrates permit significant absorption of the ink vehicle in the period immediately following printing. This tends to increase the particulate density in the cured ink film on the surface of the substrate in a similar manner associated with surface roughness.

The influence of substrate microstructure is readily observed in the strain gauge structures printed on Teslin and is primarily responsible for the dramatic increase in gauge factor values attained with structures printed on this material. This substrate contains $80 \%$ v/v of air, and can be regarded as a "honeycomb" structure of polymer permeated by air bubbles, as illustrated in Fig. 9. In deformation, the force-per-unit area in the reduced volume of polymer material is, therefore, greater than that in a "solid" substrate of the same polymer (Fig. 10). Greater substrate deformation is, therefore, obtained with Teslin for a given strain than in the other substrate materials; hence, strain sensors printed on Teslin exhibit higher gauge factor values than those printed on the remaining five substrate materials chosen for these trials.

Hysteresis observed in characterizing these printed strain sensors is attributed to mechanical changes in the conductive lithographic ink films under strain rather than changes in relative humidity or ambient temperature. To support this conclusion, future work is planned whereby ink films will be strained and

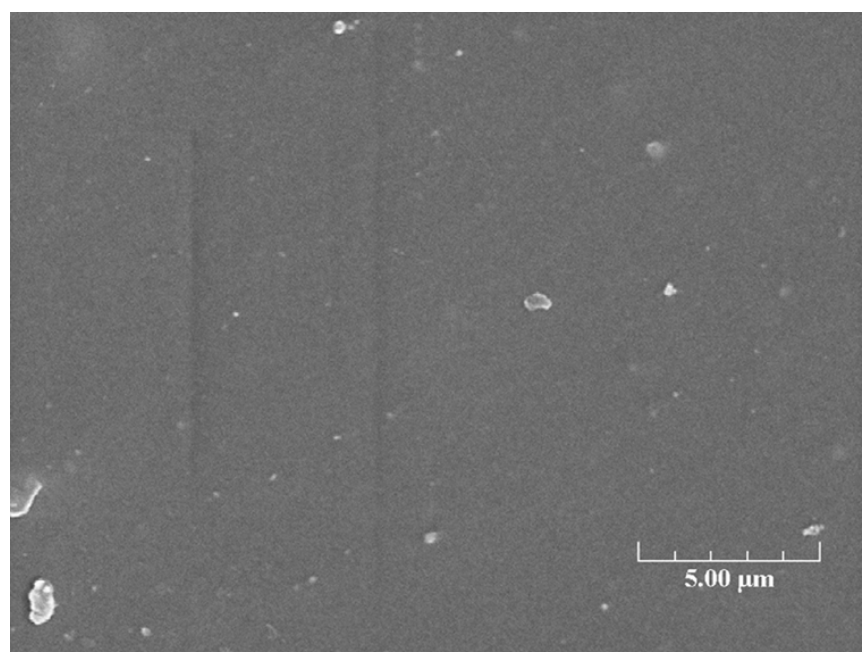

Fig. 10. Surface SEM of Mylar C substrate.

observed in an electron microscope. The result of this work will aid the understanding of ink film deformation during straining activities.

\section{ACKNOWLEDGMENT}

The authors would like to thank the staff at Rotronic Instruments, Ltd., Crawley, U.K., for their assistance in gathering data in support of this work.

\section{REFERENCES}

[1] C. C. Perry and H. R. Lissner, The Strain Gage Primer, 2nd ed. New York: McGraw-Hill, 1962.

[2] B. J. Ramsey, P. S. A. Evans, and D. J. Harrison, "A novel circuit fabrication technique using offset lithography," J. Electron. Manufact., vol. 7, no. 1, pp. 63-67, 1997.

[3] N. S. Leyland, J. R. G. Evans, and D. J. Harrison, "Lithographic printing of force-sensitive resistors," J. Mater. Sci.: Mater. Electron., vol. 13, pp. 387-390, 2002.

[4] P. R. Shepherd, C. Taylor, P. S. A. Evans, and D. J. Harrison, "Measurement and modeling of MIC components using conductive lithographic films," presented at the 31st Eur. Microwave Conf., London, U.K., 2001.

[5] P. Harrey, G. Hay, and D. Harrison, "Capacitive- type humidity sensors manufactured using offset lithography," presented at the Eurosensors XVI, Prague, Czech Republic, Sep. 2002.

[6] M. Prudenziati, B. Morten, and A. Taroni, "Characterization of thick-film resistor strain gauges on enamel steel," Sens. Actuators A, vol. 2, pp. 17-27, 1981.

[7] K. I. Arshak, F. Ansari, and D. Collins, "Analysis of thick film strain resistors on stainless steel and ceramic substrates," Int. J. Electron., vol. 76, no. 2, pp. 365-376, 1994.

[8] G. Harsanyi, "Polymer thick-film technology: A possibility to obtain very low cost pressure sensors?", Sens. Actuators A, vol. 25-27, pp. 853-857, 1991.

[9] C. Canali, D. Malavasi, B. Morten, M. Prudenziati, and A. Taroni, "Strain sensitivity in thick-film resistors," IEEE Trans. Compon. Hybrids, Manuf. Technol., vol. CHMT-3, no. 3, pp. 421-423, Sep. 1980.

[10] L. Fraigi and L. Malatto, "Thick-film weldable strain gauges," Sens. Actuators A, vol. 46-47, pp. 222-224, 1995.

[11] K. I. Arshak, A. K. Ray, C. A. Hogarth, D. G. Collins, and F. Ansari, "An analysis of polymeric thick-film resistors as pressure sensors," Sens. Actuators A, vol. 49, pp. 41-45, 1995.

[12] P. S. A. Evans, P. Harrey, B. Ramsey, and D. J. Harrison, "Lithographic film circuits-A review," J. Inst. Circuit Technol., vol. 27, no. 3, pp. 31-34, Apr. 2001

[13] R. M. Scarisbrick, Electrically Conductive Mixtures. Surrey, U.K.: Central Electricity Res. Lab.

[14] D. Delavic, M. Pavlin, S. Gramc, M. Santo-Zarnik, and M. Hrovat, "Some applications of thick-film strain gauge," presented at the IMAPS, 2000. 


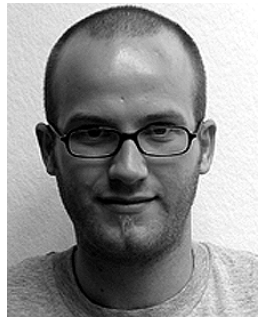

Gareth I. Hay received the B.Sc. (Hons.) in industrial design from Brunel University, Middlesex, U.K., in 2001. He is currently pursuing the Ph.D. degree at Brunel University.

He joined the Cleaner Electronics Research Group, Department of Design, Brunel University, as a Post Graduate Researcher enrolled in the doctorate program. Currently, his research concerns the printing of strain and pressure sensors by means of the offset lithographic film printing process.

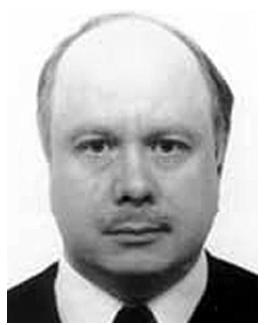

Peter S. A. Evans (M'90) received the Ph.D. degree in mixed-signal I.C. testability from the University of Huddersfield, Huddersfield, U.K., in 1994.

$\mathrm{He}$ is a Lecturer of engineering design at Brunel University, Middlesex, U.K., and a member of the EPSRC's College for Design and Integrated Production. He works in the field of novel circuit fabrication and interconnect technologies. He has ten years of experience in land mobile radio systems, acquired in industry and in the Communications Research Group, University of Bath, Bath, U.K., while subsequently undertaking research in I.C. testability at the University of Bath, and later at Huddersfield University, Huddersfield, U.K., where he devised "Transient Response Analysis," a test strategy for analog systems embedded in mixed-signal integrated circuits. He has seven years of experience in mixed-signal I.C. testability. He has published over 30 papers.

Dr. Evans is a Chartered Electrical Engineer. He is a member of the Institute of Electrical Engineers and the IEEE Test Technology Technical Council.

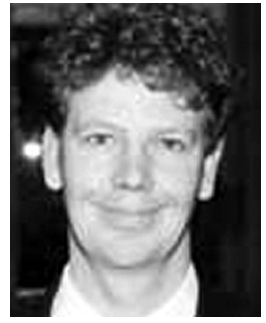

David J. Harrison received the B.Sc. degree in engineering science from Exeter University, Exeter, U.K., and the Ph.D. degree in robotics from Portsmouth Polytechnic, Portsmouth, U.K.

$\mathrm{He}$ is the Head of Research and a founder of the Environmentally Sensitive Design Group at Brunel University, Middlesex, U.K., and one of the original investigators in the field of ADSM. He has successfully patented and licensed novel technologies in printed electronics. He also sits on EPSRC panels on Sustainable Technology and Designing for the 21st Century.

Dr. Harrison is a member of the Institute of Electrical Engineers and a Chartered Engineer.

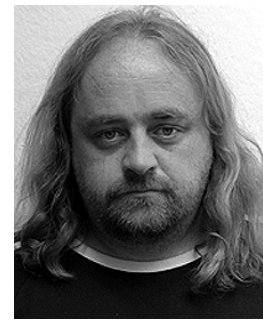

Darren Southee received the B.Eng. and M.Eng. degrees in electronic engineering from the University of Hull, Hull, U.K.

$\mathrm{He}$ spent eight years working in the electronics industry in service, production, and design roles. He designed the TD201 Digital Storage Adapter for THANDAR Electronics, Ltd. (1987) and the TA320 Logic Analyzer for TTi, Ltd. (1992). His academic career has included roles at Bournemouth University, Bournemouth, U.K., researching noninvasive blood sugar measurement, Bradford University (Etisalat College of Engineering, Sharjah, United Arab Emirates), and the University of Lincoln, Hull, U.K. He is currently Course Director for the Industrial Design and Technology Program at Brunel University, Middlesex, U.K., and a member of the Cleaner Electronics Research Group.

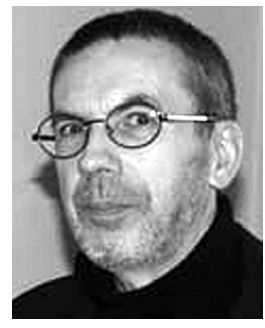

George Simpson lectures in the mechanical engineering aspects of design at Brunel University, Middlesex, U.K. His interests encompass structures, dynamics, vibrations, fluid mechanics, heat transfer, mathematics, and engineering analysis. Prior to taking up his appointment with Brunel University in 1994, he spent 17 years in industry in engineering design consultancy with YARD, Ltd. and BAeSEMA as a Principal Consultant and Section Head for computational fluid dynamics, respectively. $\mathrm{He}$ is currently the Course Director for two design courses at Brunel University: Product Design Engineering (B.Sc. program) and Mechanical Engineering and Design (M.Eng. program). His research interests include human soft tissue modeling, computational fluid dynamics, and biomimetics.

Dr. Simpson is a Chartered Engineer and Chartered Mathematician and a member of the Institution of Mechanical Engineers and of the Institute of Mathematics and its Applications.

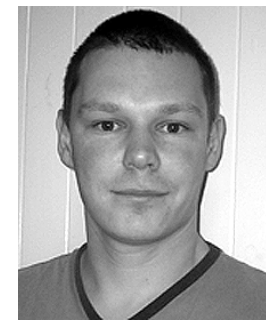

Paul M. Harrey received the B.Sc. (Hons., with a first class in industrial design) and Ph.D. degrees from Brunel University, Middlesex, U.K., in 1997 and 2003, respectively.

He joined the Cleaner Electronics Research Group, Brunel University, where he was involved in the development of the conductive lithographic film (CLF) process. His research interests include "green" manufacturing technologies and environmentally sensitive product design. He is currently working in Australia as a freelance Industrial Designer. 